\title{
Green upconversion emission in tellurite optical fibre codoped with $\mathbf{Y b}^{3+} / \mathbf{E r}^{3+}$
}

\author{
M. Kochanowicz, W. Mazerski, J. Żmojda, K. Czajkowski, D. Dorosz \\ Bialystok University of Technology, Wiejska Street 45, 15 - 351 Bialystok \\ Received February 09, 2013; accepted March 22, 2013; published March 31, 2013
}

\begin{abstract}
In the paper the spectroscopic properties of $\mathrm{Yb}^{3+} / \mathrm{Er}^{3+}$ codoped tellurite glass have been investigated. Upconversion luminescence at $525 \mathrm{~nm}, 546 \mathrm{~nm}, 651 \mathrm{~nm}$ corresponding to the $\mathrm{Er}^{3+}$ : ${ }^{2} \mathrm{H}_{11 / 2} \rightarrow{ }^{4} \mathrm{I}_{15 / 2}, \quad{ }^{4} \mathrm{~S}_{3 / 2} \rightarrow{ }^{4} \mathrm{I}_{15 / 2},{ }^{4} \mathrm{~F}_{9 / 2} \rightarrow{ }^{4} \mathrm{I}_{15 / 2}$ transitions, respectively was obtained as a result of energy transfer between $\mathrm{Yb}^{3+}$ and $\mathrm{Er}^{3+}$ ions. The developed tellurite glass characterized by the highest intensity of upconversion luminescence $\left(0.5 \mathrm{~mol} \% \mathrm{Yb}_{2} \mathrm{O}_{3} / 0.1 \mathrm{~mol} \% \mathrm{Er}_{2} \mathrm{O}_{3}\right)$ was used as a core of optical fiber. The amplified spontaneous emission in the fabricated optical fiber resulting from the optical transition in the structure of erbium was observed.
\end{abstract}

Upconversion luminescence of glasses doped with rareearth ions have attracted much attention during the last decade due to their potential applications in solid-state lasers, colour displays, optical data storages, medical diagnostics, optical sensors [1-4]. Upconverting glass host should be characterized by relatively low phonon energy which makes it possible to obtain high upconversion luminescence efficiency. Tellurite glasses, thanks to perfect solubility of rare earth elements as well as low phonon energy $\left(\sim 780 \mathrm{~cm}^{-1}\right)$ enable an effective conversion of IR radiation to VIS radiation and make a perfect alternative to fluoride as well as to HMO glasses [5]. Furthermore, their excellent mechanical properties as well as high thermal stability make it possible to form them into optical fibers. The article presents the results of the optimization of acceptor concentration in $\mathrm{Yb}^{3+} / \mathrm{Er}^{3+}$ codoped glass from $\mathrm{TeO}_{2}-\mathrm{GeO}_{2}-\mathrm{PbO}-\mathrm{PbF}_{2}-\mathrm{BaO}-$ $\mathrm{Nb}_{2} \mathrm{O}_{5}-\mathrm{LaF}_{3}$ system in order to obtain the highest intensity of green upconversion emission. The core of optical fiber was made of glass characterized by the highest green upconversion and comparative analysis of luminescent properties of bulk glass and optical fiber was conducted.

The glass system: $\mathrm{TeO}_{2}-\mathrm{GeO}_{2}-\mathrm{PbO}-\mathrm{PbF}_{2}-\mathrm{BaO}-$ $\mathrm{Nb}_{2} \mathrm{O}_{5}-\mathrm{LaF}_{3}$ codoped with $\mathrm{Yb}^{3+} / \mathrm{Er}^{3+}$ ions was melted from spectrally pure $(99.99 \%)$ raw materials. The homogenized set was placed in a platinum crucible and melted in an electric furnace in a temperature of $900^{\circ} \mathrm{C}$ for 30 minutes in an argon atmosphere. The molten glass was poured out onto a brass plate and then exposed to the process of annealing in a temperature approximate to the transformation temperature for 12 hours. Homogenous and transparent glasses were obtained without any visible effect of crystallization. In order to determine the spectroscopic properties a series of samples with the dimensions of $10 \times 10 \times 2 \mathrm{~mm}^{3}$ was prepared. The glass density was calculated using the method of hydrostatic weighing. The refractive index $(633 \mathrm{~nm})$ was determined using a Metricon 2010 refractometer. The characteristic temperatures of the obtained glasses were calculated on the basis of measurements taken with a SETARAM Labsys thermal analyzer using the DSC method. Absorption spectra of rare earth ions doped samples were determined using an Acton Spectra Pro 2300i monochromator in a spectral range of $350 \div 1700 \mathrm{~nm}$. The tellurite optical fiber was manufactured by using a modified for the purpose, double - crucible technique [6]. Luminescence spectra in a range of $450 \div 750 \mathrm{~nm}$ were measured by using a Stelarnet GreenWave spectrometer and a high power laser diode $\left(\lambda_{\mathrm{p}}=976 \mathrm{~nm}\right)$ as a pump source.

The parameters of tellurium-based glasses codoped with $\mathrm{Yb}^{3+} / \mathrm{Er}^{3+}$ are presented in Table 1. Tellurite glasses are characterised by a high coefficient of light refraction (2.07), which is the cause of a high value of the emission cross-section. Furthermore, the complex composition of the obtained tellurite glasses made it possible to introduce significant amounts of rare earth elements to the matrix. 
Table 1. Physical and thermal properties of manufactured tellurite glass.

\begin{tabular}{cc}
\hline Parameter & Value \\
\hline Refractive index $n(633 \mathrm{~nm})$ & 2.074 \\
Mass density $\rho\left[\mathrm{g} / \mathrm{cm}^{3}\right]$ & 6.21 \\
Thermal expansion coefficient $\alpha_{100}^{400}\left[10^{-7} 1 / \mathrm{K}\right]$ & 108.9 \\
Dilatometric softening point $T_{s}\left[{ }^{\circ} \mathrm{C}\right]$ & 364 \\
Transformation temperature $T_{g}\left[{ }^{\circ} \mathrm{C}\right](\mathrm{DSC})$ & 345 \\
Maximum of phonon energy $h \omega_{\text {maax }}\left[\mathrm{cm}^{-1}\right]$ & 790 \\
\hline
\end{tabular}

Based on transmission spectra measurement the absorption coefficient spectrum of the obtained tellurite glass codoped with $\mathrm{Er}^{3+} / \mathrm{Yb}^{3+}$ ions (Fig. 1) was calculated. The absorption bands resulting from the complex structure of erbium corresponding to the following transitions: ${ }^{4} \mathrm{I}_{15 / 2}$ $\rightarrow{ }^{4} \mathrm{~F}_{7 / 2},{ }^{2} \mathrm{H}_{11 / 2},{ }^{4} \mathrm{~F}_{9 / 2},{ }^{4} \mathrm{I}_{9 / 2},{ }^{4} \mathrm{I}_{11 / 2},{ }^{4} \mathrm{I}_{13 / 2}$

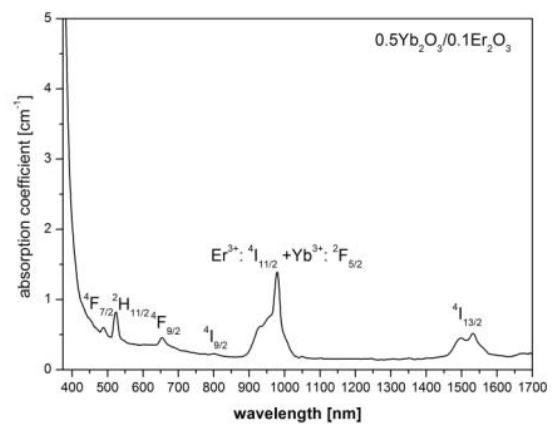

Fig. 1. Absorption spectra of fabricated tellurite glass codoped with $0.5 \mathrm{~mol} \% \mathrm{Yb}_{2} \mathrm{O}_{3} / 0.1 \mathrm{~mol} \% \mathrm{Er}_{2} \mathrm{O}_{3}$.

A wide absorption band around $980 \mathrm{~nm} \mathrm{Yb}^{3+} / \mathrm{Er}^{3+}$ codoped glasses resulting from spectral overlap between $\mathrm{Yb}^{3+}$ emission $\left({ }^{2} \mathrm{~F}_{5 / 2} \rightarrow{ }^{2} \mathrm{~F}_{7 / 2}\right)$ and $\operatorname{Er}^{3+}$ absorption $\left({ }^{4} \mathrm{I}_{15 / 2} \rightarrow\right.$ $\left.{ }^{4} \mathrm{I}_{11 / 2}\right)$.

Figure 2 presents the emission spectra of tellurite glasses codoped with $\mathrm{Yb}^{3+} / \mathrm{Er}^{3+}$ ions. As a result of exciting glasses with the $976 \mathrm{~nm}$ wavelength radiation, three antiStokes emission bands: $525 \mathrm{~nm}, 546 \mathrm{~nm}, 651 \mathrm{~nm}$ corresponding to the ${ }^{2} \mathrm{H}_{11 / 2} \rightarrow{ }^{4} \mathrm{I}_{15 / 2}, \quad{ }^{4} \mathrm{~S}_{3 / 2} \rightarrow{ }^{4} \mathrm{I}_{15 / 2}$, $\left({ }^{4} \mathrm{~F}_{9 / 2} \rightarrow{ }^{4} \mathrm{I}_{15 / 2}\right.$ ) transitions, respectively (Fig. 2), were measured. The concentration of $\mathrm{Yb}_{2} \mathrm{O}_{3}(0.5 \mathrm{~mol} \%)$ on the one hand results from maximization of the sensitization process and, on the other hand, it is limited by clustering.

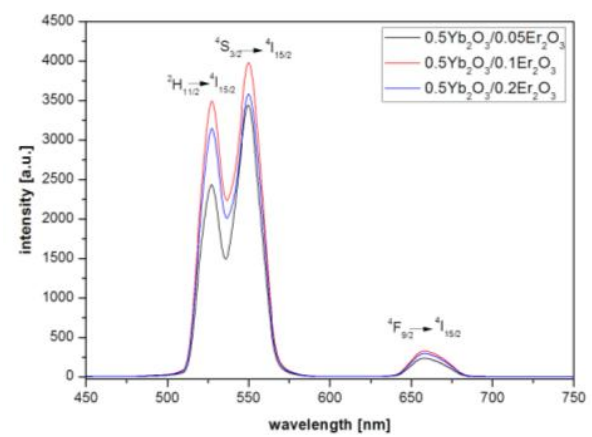

Fig. 2. Upconversion luminescence spectrum of $\mathrm{Yb}^{3+} / \mathrm{Er}^{3+}$ codoped tellurite glasses.

The analysis of emission intensity as a function of $\mathrm{Er}_{2} \mathrm{O}_{3}$ molar concentration has shown that the maximum of upconversion luminescence was obtained in the glass $\begin{array}{llll}\text { codoped with } \quad 0.5 \mathrm{~mol} \% & \mathrm{Yb}_{2} \mathrm{O}_{3} / 0.1 \mathrm{~mol} \% & \mathrm{Er}_{2} \mathrm{O}_{3}\end{array}$ (TeGe_05Y01E). The fall in the emission intensity of glass codoped with $0.5 \mathrm{~mol} \% \quad \mathrm{Yb}_{2} \mathrm{O}_{3} / 0.2 \mathrm{~mol} \% \quad \mathrm{Er}_{2} \mathrm{O}_{3}$ results from concentration quenching. The energy level scheme with mechanisms of upconversion emission from $\mathrm{Er}^{3+}$ ion in the presence of $\mathrm{Yb}^{3+}$ under $976 \mathrm{~nm}$ excitation is shown in Fig. 3. The population of $\mathrm{Er}^{3+}$ metastable levels occurs mainly as a result of resonance energy transfer $\mathrm{Yb}^{3+} \rightarrow \mathrm{Er}^{3+}$. Green emission resulting from energy transfer and upconversion processes takes place according to the following scheme:

(ET) ${ }^{2} \mathrm{~F}_{5 / 2}\left(\mathrm{Yb}^{3+}\right)+{ }^{4} \mathrm{I}_{15 / 2}\left(\mathrm{Er}^{3+}\right) \rightarrow{ }^{2} \mathrm{~F}_{7 / 2}\left(\mathrm{Yb}^{3+}\right)+{ }^{4} \mathrm{I}_{11 / 2}\left(\mathrm{Er}^{3+}\right),(\mathrm{GSA})$

${ }^{4} \mathrm{I}_{5 / 2}\left(\mathrm{Er}^{3+}\right)+$ photon $\rightarrow{ }^{4} \mathrm{I}_{11 / 2}\left(\mathrm{Er}^{3+}\right)$.

(CR) ${ }^{4} \mathrm{I}_{11 / 2}\left(\mathrm{Er}^{3+}\right)+{ }^{4} \mathrm{I}_{11 / 2}\left(\mathrm{Er}^{3+}\right) \rightarrow{ }^{4} \mathrm{I}_{15 / 2}\left(\mathrm{Er}^{3+}\right)+{ }^{4} \mathrm{~F}_{7 / 2}\left(\mathrm{Er}^{3+}\right),(\mathrm{ESA})^{4} \mathrm{I}_{11 / 2}\left(\mathrm{Er}^{3+}\right)$ + photon $\rightarrow{ }^{4} \mathrm{~F}_{7 / 2}\left(\mathrm{Er}^{3+}\right)^{2} \mathrm{~F}_{5 / 2}\left(\mathrm{Yb}^{3+}\right)+{ }^{4} \mathrm{I}_{11 / 2}\left(\mathrm{Er}^{3+}\right) \rightarrow{ }^{2} \mathrm{~F}_{7 / 2}\left(\mathrm{Yb}^{3+}\right)+{ }^{4} \mathrm{~F}_{7 / 2}\left(\mathrm{Er}^{3+}\right)$.

In the next step, the nonradiative relaxation ${ }^{4} \mathrm{~F}_{7 / 2} \rightarrow{ }^{2} \mathrm{H}_{11 / 2}$, ${ }^{4} \mathrm{~S}_{3 / 2}$ and emission at $525 \mathrm{~nm}\left({ }^{2} \mathrm{H}_{11 / 2} \rightarrow{ }^{4} \mathrm{I}_{15 / 2}\right)$, 546nm $\left({ }^{4} \mathrm{~S}_{3 / 2} \rightarrow{ }^{4} \mathrm{I}_{15 / 2}\right), 651 \mathrm{~nm}\left({ }^{4} \mathrm{~F}_{9 / 2} \rightarrow{ }^{4} \mathrm{I}_{15 / 2}\right)$ takes place.

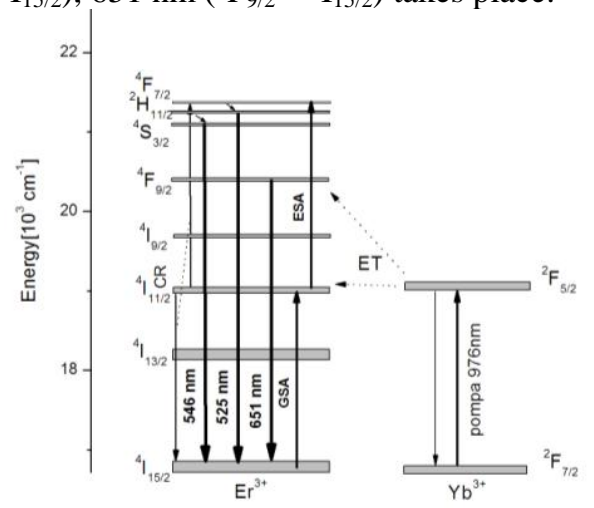

Fig. 3. Simplified diagram of energy level $\mathrm{Yb}^{3+} / \mathrm{Er}^{3+}$ with energy transfer mechanism. 
The efficiency of the above upconversion process depends on the lifetime of excited levels $\mathrm{Er}^{3+}$, concentration of active dopant influencing the multiphonon relaxation and cross - relaxation.

Figure 4 presents the cross-section of the fabricated tellurite optical fiber codoped with $0.5 \mathrm{~mol} \% \mathrm{Yb}_{2} \mathrm{O}_{3} /$ $0.1 \mathrm{~mol} \% \mathrm{Er}_{2} \mathrm{O}_{3}$.

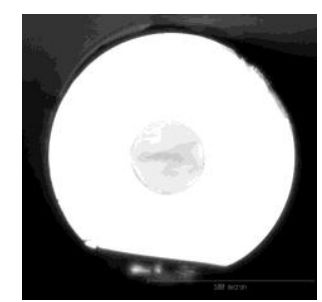

Fig. 4. Cross-section of the fabricated tellurite optical fiber codoped with $0.5 \mathrm{~mol} \% \mathrm{Yb}_{2} \mathrm{O}_{3} / 0.1 \mathrm{~mol} \% \mathrm{Er}_{2} \mathrm{O}_{3}$.

Table 2. Parameters of the fabricated tellurite optical fiber codoped with $0.5 \mathrm{~mol} \% \mathrm{Yb}_{2} \mathrm{O}_{3} / 0.1 \mathrm{~mol} \% \mathrm{Er}_{2} \mathrm{O}_{3}$.

\begin{tabular}{cc}
\hline Parameter & Value \\
\hline Cladding diameter $[\mu \mathrm{m}]$ & 165 \\
Core diameter $[\mu \mathrm{m}]$ & 45 \\
Numerical aperture $N A$ & 0.56 \\
\hline
\end{tabular}

The relatively high value of numerical aperture NA $=0.56$ (Table 2) allows efficient coupling of pump radiation with produced optical fiber.

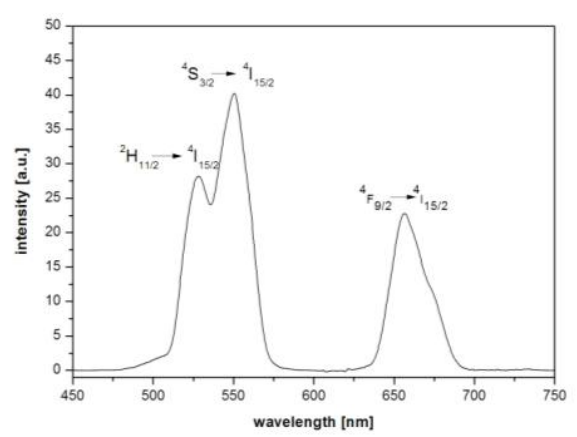

Fig. 5. The luminescence spectra of fabricated tellurite optical fibre codoped with $\mathrm{Er}^{3+} 0.5 \mathrm{~mol} \% \mathrm{Yb}_{2} \mathrm{O}_{3} / 0.1 \mathrm{~mol} \% \mathrm{Er}_{2} \mathrm{O}_{3}$ under $976 \mathrm{~nm}$ LD excitation.

Similarly as in the bulk glass, the luminescence spectra of the produced tellurite optical fiber $\left(\lambda_{\mathrm{p}}=976 \mathrm{~nm}\right)$ consist of three anti-stokes emission bands: 529nm $\left({ }^{2} \mathrm{H}_{11 / 2} \rightarrow{ }^{4} \mathrm{I}_{15 / 2}\right)$, $550 \mathrm{~nm}\left({ }^{4} \mathrm{~S}_{3 / 2} \rightarrow{ }^{4} \mathrm{I}_{15 / 2}\right)$ and $656 \mathrm{~nm}\left({ }^{4} \mathrm{~F}_{9 / 2} \rightarrow{ }^{4} \mathrm{I}_{15 / 2}\right)$ as shown in Fig. 5. However, the ratio of intensity emission $545 \mathrm{~nm} / 525 \mathrm{~nm}$ in the optical fiber is higher than in the case of TeGe_05Y01E bulk glass. Decreasing emission intensity of bulk glass at $545 \mathrm{~nm}$ and simultaneous increasing emission intensity at $525 \mathrm{~nm}$ is caused by the thermal population of ${ }^{2} \mathrm{H}_{11 / 2}$ level. The bulk glass sample is warming up during the pumping process. Moreover, measured emission bands shift towards a longer wavelength of $4 \mathrm{~nm}(550 \mathrm{~nm}$ and $656 \mathrm{~nm})$ as a function of the fiber length. This phenomenon is related to the reabsorption of ASE signal resulting from the $\mathrm{Er}^{3+}$ : ${ }^{5} \mathrm{I}_{15 / 2} \rightarrow{ }^{2} \mathrm{H}_{11 / 2},{ }^{5} \mathrm{I}_{15 / 2} \rightarrow{ }^{4} \mathrm{~F}_{9 / 2}$ transition, which was confirmed in the course of an experiment with different fiber lengths. Besides, the red/green intensity ratio is much larger in the optical fiber. A similar phenomenon has been presented in the literature [1]. However, an in-depth explanation requires further investigation.

In the present article the spectroscopic properties of tellurite glass and optical fiber codoped with $\mathrm{Yb}^{3+} / \mathrm{Er}^{3+}$ ions were investigated. As a result of optimized acceptor concentration, the best efficiency of energy transfer $\mathrm{Yb}^{3+} \rightarrow \mathrm{Er}^{3+}$ was obtained for molar composition $0.5 \mathrm{~mol} \%$ $\mathrm{Yb}_{2} \mathrm{O}_{3} / 0.1 \mathrm{~mol} \% \quad \mathrm{Er}_{2} \mathrm{O}_{3}$. Fabricated tellurite glass characterized by highest intensity of upconversion luminescence $\left(0.5 \mathrm{~mol} \% \quad \mathrm{Yb}_{2} \mathrm{O}_{3} / 0.1 \mathrm{~mol} \% \mathrm{Er}_{2} \mathrm{O}_{3}\right)$ was used as a core of optical fiber. The spectroscopic properties of the fabricated tellurite optical fiber $\left(\lambda_{p}=976 \mathrm{~nm}\right)$ were significantly different from the bulk glass. Emission bands of the produced optical fiber shift towards the longer wavelength of $4 \mathrm{~nm}(550 \mathrm{~nm}$ and $656 \mathrm{~nm})$ as a function of fiber length. This phenomenon is related to the reabsorption of ASE signal resulting from the $\mathrm{Er}^{3+}$ : ${ }^{5} \mathrm{I}_{15 / 2} \rightarrow{ }^{2} \mathrm{H}_{11 / 2}, \quad{ }^{5} \mathrm{I}_{15 / 2} \rightarrow{ }^{4} \mathrm{~F}_{9 / 2}$ transition and enables the optimization of the emission spectra of optical fiber. Upconversion amplified spontaneous emission (UASE) in the produced tellurite optical fiber codoped with $0.5 \mathrm{~mol} \%$ $\mathrm{Yb}_{2} \mathrm{O}_{3} / 0.1 \mathrm{~mol} \% \quad \mathrm{Er}_{2} \mathrm{O}_{3}$ indicates viable numerous applications of the developed optical fiber in biophotonics.

This work was supported by MNiSW project No. $\mathrm{MB} / \mathrm{WE} / 1 / 2012$.

\section{References}

[1] J. Zhang, S. Dai, G. Wang, L. Zhang, H. Sun, L. Hu., Phys. Lett. A 345, 409 (2005).

[2] D. Lande, S.S. Orlov, A. Akella, L. Hesselink, R.R. Neurgaonkar, Opt. Lett. 22(22), 1722 (1997).

[3] T. Yamashita, Y. Ohishi, Proc. SPIE 6389, 638912 (2006).

[4] Y.H. Li, G.Y. Hong, Y.M. Zhang, Y.M. Yu, J. Alloys Compd. 456, 247 (2008).

[5] J.S. Wang, E.M. Vogel, E. Snitzer, Opt. Mater. 3, 187 (1994)

[6] J. Dorosz, Ceramics 86 (2005). 